\title{
Young Woman with Sudden-Onset Neck Pain and Quadriplegia: a Case Report
}

\author{
Koshi Ota $^{1}$ (D) Shoji Ogawa ${ }^{2} \cdot$ Kensuke Fujii $^{1} \cdot$ Yasuo Oishi $^{1} \cdot$ Masahiro Oka $^{1} \cdot$ Naoya Onishi $^{1} \cdot$ Kanna Ota $^{1}$. \\ Yohei Sano $^{1} \cdot$ Hiroki Yokoyama $^{1} \cdot$ Akira Takasu $^{1}$
}

Accepted: 26 April 2021 / Published online: 1 May 2021

(C) The Author(s) 2021

\begin{abstract}
Introduction Sudden-onset quadriplegia is a neurologic emergency that requires immediate management. Anterior spinal artery syndrome (ASAS) is rare, but can cause sudden-onset quadriplegia. Magnetic resonance imaging (MRI) is an essential imaging modality for diagnosing ASAS.

Case Presentation A 31-year-old woman without previous medical history was transferred to our facility for further workup of sudden-onset neck pain with quadriplegia. Diffusion-weighted imaging (DWI) revealed hyperintense signals predominantly in grey matter with a decreased apparent diffusion coefficient (ADC). These findings strongly suggested ASAS with spinal cord infarction. Edaravone, heparin, and aspirin with steroid pulse therapy were immediately initiated. Twelve days in an intensive care unit was required for dyspnea. Symptoms gradually resolved with rehabilitation, but the patient was wheelchair-bound without bladder control and was transferred to a rehabilitation facility on hospital day 48.

Conclusion A combination of DWI with ADC mapping of the spine should proceed as soon as possible to ensure appropriate management. Early treatment with edaravone, aspirin, and steroid pulse therapy may prove beneficial for ASAS.
\end{abstract}

Keywords ASAS $\cdot$ Anterior spinal artery syndrome $\cdot$ Edaravone $\cdot$ Quadriplegia $\cdot$ Sudden-onset

\section{Introduction}

Abrupt onset of quadriplegia is a neurologic emergency that requires immediate management $[1,2]$. Several etiologies can cause the sudden onset of quadriplegia or quadriparesis [2].

This article is part of the Topical Collection on Medicine
Anterior spinal artery syndrome (ASAS) is one of these differential diagnoses and is a lesion affecting the anterior twothirds of the spinal cord including the anterior horns of the gray matter, the spinothalamic tract, and the corticospinal tract, with weakness and sensory loss but spared

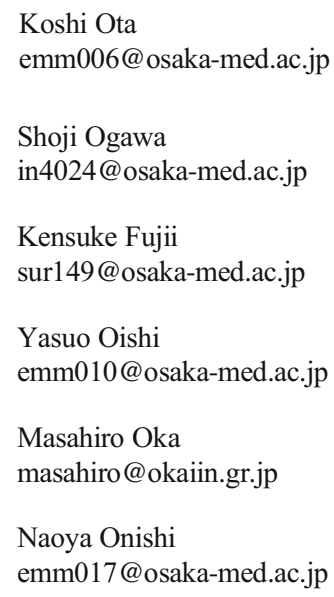

\author{
Kanna Ota \\ kanna.nonaka@gmail.com \\ Yohei Sano \\ youheisano3@gmail.com \\ Hiroki Yokoyama \\ emm018@osaka-med.ac.jp \\ Akira Takasu \\ takasu@osaka-med.ac.jp \\ 1 Department of Emergency Medicine, Osaka Medical College, 2-7 \\ Daigaku-machi, Takatsuki City, Osaka 596-8686, Japan \\ 2 Division of Neurology, Department of Internal Medicine IV, Osaka \\ Medical College, 2-7 Daigaku-machi, Takatsuki \\ City, Osaka 596-8686, Japan
}


proprioception (body position in space and vibratory sense) [3]. A combination of diffusion-weighted imaging (DWI) with apparent diffusion coefficient (ADC) mapping of the spine is essential to detect the cause of ASAS, such as spinal cord infarction, spinal cord angioma, metastatic spinal carcinoma, or acute epidural hematoma $[4,5]$. However, reading MRI of the spine is difficult, especially for primary-care physicians treating early-stage disease [6]. Here, we describe the case of a previously healthy young woman in whom ASAS with spinal cord infarction was detected on magnetic resonance imaging (MRI) soon after arrival in our emergency room (ER). Informed consent was obtained from the patient and documented based on local regulations.

\section{Case Report}

A previously healthy 31-year-old woman experienced sudden onset of neck pain with left arm discomfort 2 days before admission, but did not seek medical attention. She had no history of trauma, and her familial medical histories included breast cancer in her older sister and maternal grandmother, and rheumatoid arthritis and diabetes mellitus in her maternal grandfather. On the morning of her admission, she developed very severe neck pain at 7:30 in the morning with acute flaccid paralysis of the arms. She was brought to the nearest hospital in an ambulance, was diagnosed with sprained neck after cervical X-ray, and was discharged to home. She was able to walk with the help of her husband at that time. However, paralysis of the legs deteriorated with neck pain at 19:30 and she was brought to another hospital and underwent computed tomography (CT) of the brain and neck, showing no abnormalities. The patient was then transferred to our facility for further workup of neck pain with quadriplegia. Vital signs on arrival at the ER were the following: body temperature, $36.4{ }^{\circ} \mathrm{C}$; heart rate, 98 beats/min; respiratory rate, 18 breaths/min; blood pressure, 107/67 mmHg; and peripheral oxygen saturation $\left(\mathrm{SpO}_{2}\right), 98 \%$ on ambient air. Speech, cognition, and cranial nerve function remained normal. Manual muscle testing (MMT) showed left-right symmetry of findings (Table 1). Passive range of motion in all extremities was complete, with no pain or spasticity. Reflexes were bilaterally absent for the biceps, triceps, and brachioradialis, and of the patellar and Achilles tendon reflexes, and Babinski sign was also absent bilaterally. Proprioception (body position in space and vibratory sense) was preserved, but pain and temperature sensation were lost below the T4 level bilaterally. Urinary incontinence also developed and a urethral catheter was inserted. Whole-body CT findings including the cervical, thoracic, and lumbar spine were normal. Initial MRI examination 30 min after arrival revealed abnormal T2 signals in the cervical spine from $\mathrm{C} 3$ to $\mathrm{T} 1$ without cord compression (Fig. 1a, b). A neurologist was consulted under a potential
Table 1 Findings from manual muscle testing

\begin{tabular}{llllll}
\hline & \multicolumn{2}{l}{ On arrival } & & \multicolumn{2}{l}{ 48 days later } \\
\cline { 2 - 3 } \cline { 6 - 7 } \cline { 5 - 6 } & Right & Left & & Right & Left \\
\hline Shoulder abduction & $4 / 5$ & $3 / 5$ & & $5 / 5$ & $4 / 5$ \\
Elbow flexion & $0 / 5$ & $0 / 5$ & & $4 / 5$ & $3 / 5$ \\
Elbow extension & $0 / 5$ & $0 / 5$ & & $3 / 5$ & $3 / 5$ \\
Wrist extension & $0 / 5$ & $0 / 5$ & & $3 / 5$ & $3 / 5$ \\
Wrist flexion & $0 / 5$ & $0 / 5$ & & $3 / 5$ & $3 / 5$ \\
Grip strength & $0 / 5$ & $0 / 5$ & & $3 / 5$ & $3 / 5$ \\
Thumb adduction & $0 / 5$ & $0 / 5$ & $3 / 5$ & $3 / 5$ \\
Thumb abduction & $0 / 5$ & $0 / 5$ & & $3 / 5$ & $3 / 5$ \\
Interossei muscles & $0 / 5$ & $0 / 5$ & & $3 / 5$ & $3 / 5$ \\
Hip flexion & $0 / 5$ & $0 / 5$ & & $3 / 5$ & $3 / 5$ \\
Hip extension & $0 / 5$ & $0 / 5$ & & $3 / 5$ & $3 / 5$ \\
Hip adduction & $0 / 5$ & $0 / 5$ & & $3 / 5$ & $3 / 5$ \\
Hip abduction & $0 / 5$ & $0 / 5$ & & $3 / 5$ & $3 / 5$ \\
Knee flexion & $0 / 5$ & $0 / 5$ & & $3 / 5$ & $3 / 5$ \\
Knee extension & $0 / 5$ & $0 / 5$ & $3 / 5$ & $3 / 5$ \\
Ankle dorsiflexion & $0 / 5$ & $0 / 5$ & $3 / 5$ & $3 / 5$ \\
Ankle plantarflexion & $0 / 5$ & $0 / 5$ & $3 / 5$ & $3 / 5$ \\
\hline
\end{tabular}

diagnosis of ASAS. Repeat MRI with DWI and ADC mapping $3 \mathrm{~h}$ later revealed hyperintense signals predominantly in the grey matter, and a contrast T2 signal abnormality with decreased ADC (Fig. 1c, d). Cerebrospinal fluid (CSF) obtained via lumbar puncture on the day of admission showed: white blood cells, 0 cells $/ \mathrm{mm}^{3}$; red blood cells, 1 cell $/ \mathrm{mm}^{3}$; total protein, $53.9 \mathrm{mg} / \mathrm{dL}$ (normal, $15-45 \mathrm{mg} / \mathrm{dL}$ ); and glucose, $57 \mathrm{mg} / \mathrm{dL}$ (normal, 70-110 mg/dL). Hematological and biochemical findings including autoimmune-associated vasculitis, infections, and hypercoagulopathies were mostly within normal ranges, except for mildly decreased potassium (3.4 $\mathrm{mmol} / \mathrm{L}$; normal range 3.6-4.8). ASAS was finally diagnosed after excluding other diagnoses. We started edaravone, heparin, and aspirin with steroid pulse therapy (methylprednisolone, $1000 \mathrm{mg}$ /day) to prevent swelling of the spine, but this did not completely improve the neurological deficits. The next day, she complained of dyspnea and aspiration occurred after drinking water and was transferred to the intensive care unit (ICU) to secure the airway. Intubation was planned initially, but was not performed, because she could breathe by herself. She was therefore moved to a general ward after 12 days in the ICU. DWI on hospital day 13 revealed enlargement of hyperintense signals predominantly in the grey matter from $\mathrm{C} 3$ to $\mathrm{T} 3$, and contrast $\mathrm{T} 2$ signal abnormality with a decreased $\mathrm{ADC}$ (Fig. 2). MRI findings on hospital days 18 and 28 were better and infarctions showed decreased size compared with the findings from hospital day 13 (Fig. 3). The patient started to gradually recover and could eat by herself using her left hand, 
Fig. 1 MRI findings on

admission and after $3 \mathrm{~h}$. a Sagittal T2-weighted imaging (repetition time (TR) $3000 \mathrm{~ms}$, echo time (TE) $106.20 \mathrm{~ms}$ ) shows signal hyperintensity from $\mathrm{C} 3$ to $\mathrm{T} 1$ (arrows). b Axial T2-weighted imaging (TR $3116.67 \mathrm{~ms}$, TE $93.16 \mathrm{~ms}$ ) shows signal hyperintensity with involvement of grey matter and adjacent central white matter (arrow). c Sagittal DWI imaging (TR 7000 $\mathrm{ms}$, TE $72.70 \mathrm{~ms}$ ) shows signal hyperintensity from $\mathrm{C} 3$ to $\mathrm{T} 1$ (arrow), as in a. d Axial ADC mapping (TR $7000 \mathrm{~ms}$, TE 72.70 $\mathrm{ms}$ ) shows a slightly dark area from $\mathrm{C} 3$ to $\mathrm{T} 1$ (arrow), as in $\mathbf{a}$ and

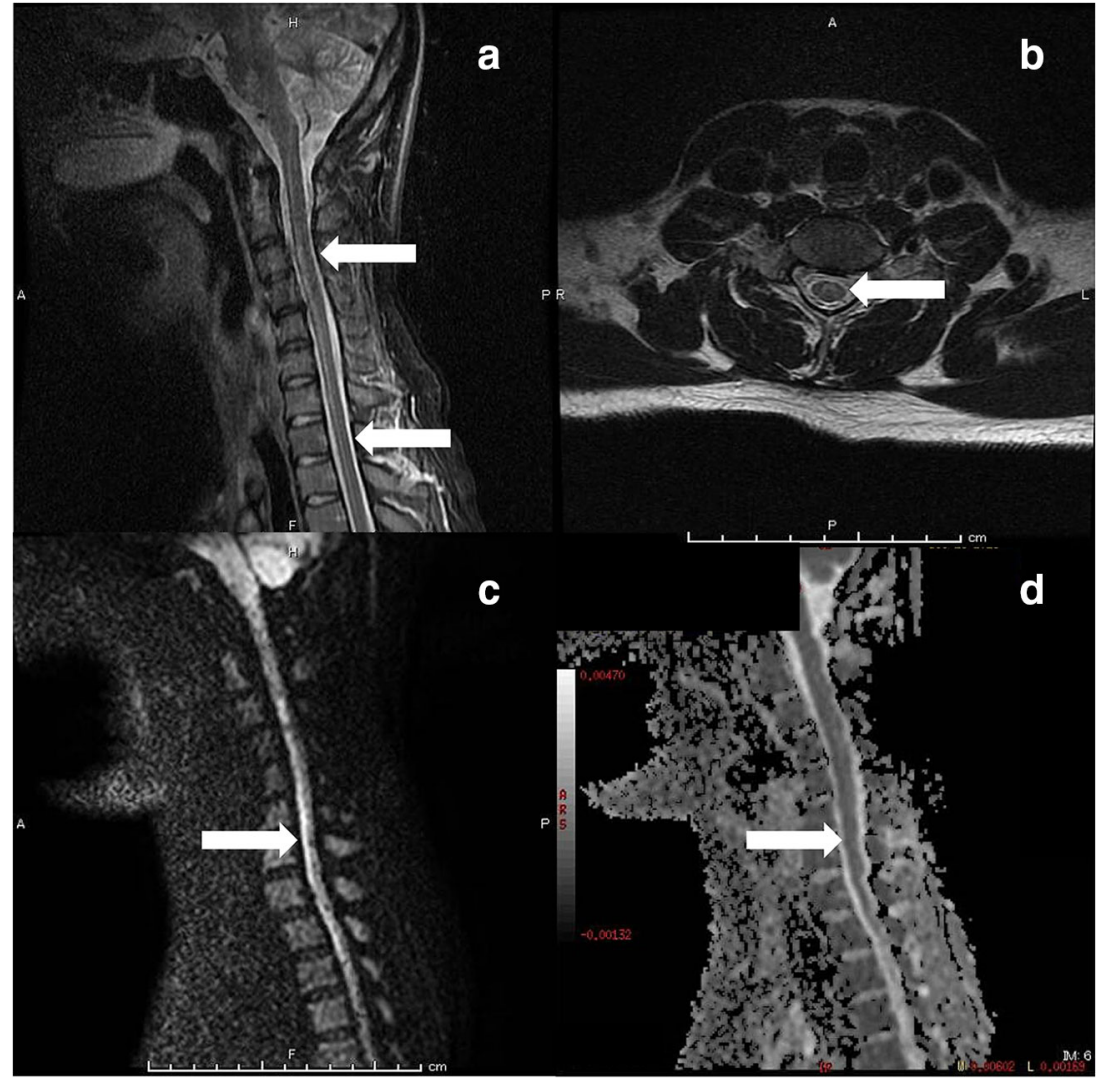

b

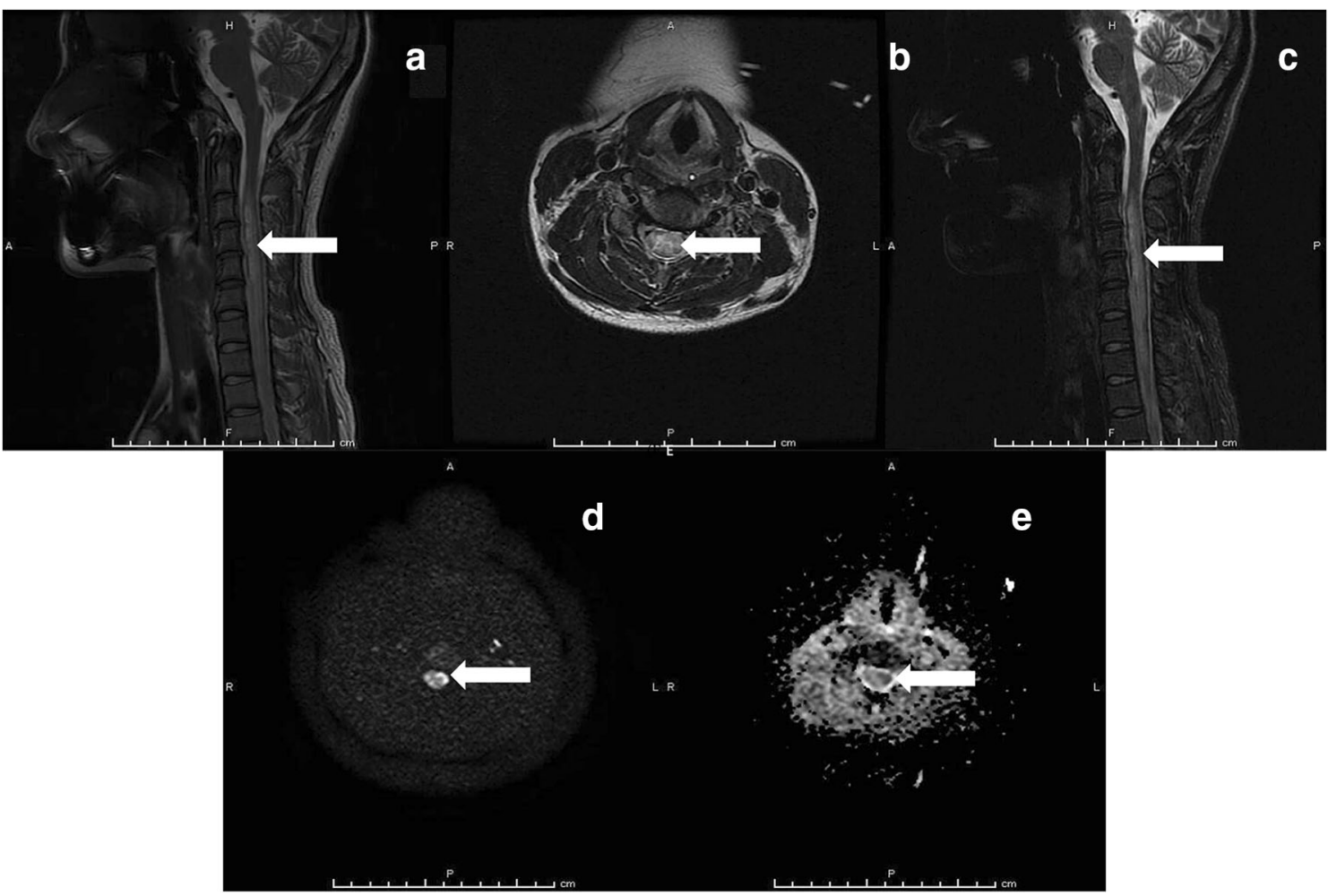

Fig. 2. MRI findings on hospital day 13. Signal hyperintensity with spinal swelling from $\mathrm{C} 3$ to $\mathrm{T} 1$ (arrow) on a sagittal T2-weighted imaging (TR $3000 \mathrm{~ms}$, TE $104 \mathrm{~ms}$ ) image, b axial T2-weighted (TR $3716.67 \mathrm{~ms}$, TE $102.58 \mathrm{~ms}$ ) image (arrow), and c sagittal short TI inversion recovery imaging (TR $3500 \mathrm{~ms}$, TE $81.58 \mathrm{~ms}$ ) (arrow). d Axial DWI (TR $6575 \mathrm{~ms}$; TE $79.70 \mathrm{~ms}$ ) shows signal hyperintensity (arrow) and e ADC mapping (TR $6575 \mathrm{~ms}$, TE $79.70 \mathrm{~ms}$ ) shows a dark area (arrow) 
Fig. 3 MRI findings on hospital days 18 and 28. a Hyperintense signal persists on sagittal T2weighted (TR $3000 \mathrm{~ms}$, TE $101.64 \mathrm{~ms}$ ) and b axial T2weighted imaging (TR $4600 \mathrm{~ms}$, TE $104.16 \mathrm{~ms}$ ) (arrow) on hospital day 18. c Signal hyperintensity is reduced on sagittal T2-weighted (TR 3350 $\mathrm{ms}, \mathrm{TE} 84.48 \mathrm{~ms}$ ) and $\mathbf{d}$ axial T2weighted imaging (TR $2700 \mathrm{~ms}$, TE $102.49 \mathrm{~ms}$ ) (arrow) on hospital day 28

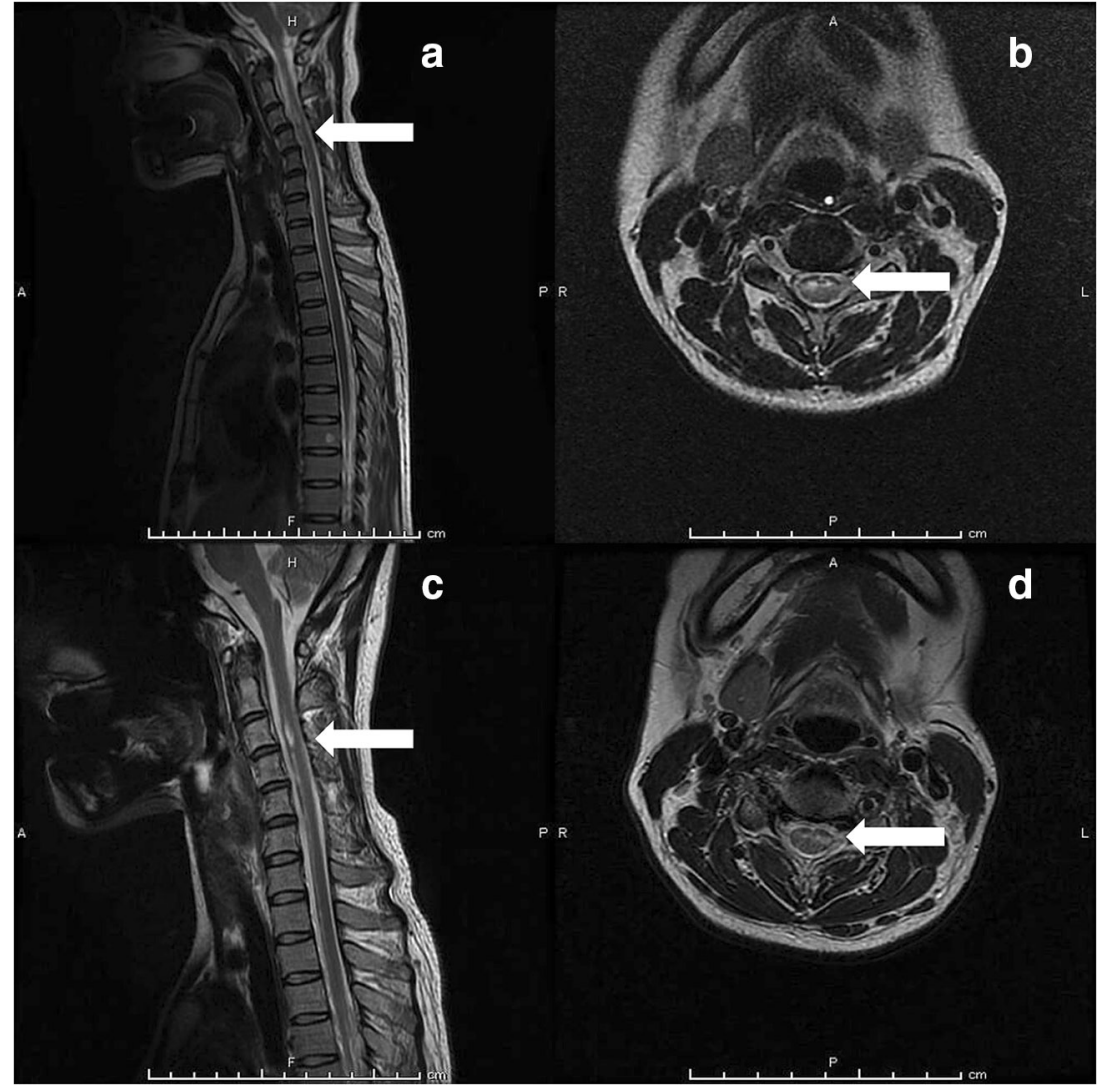

although she needed a wheelchair and urethral catheter. She was transferred to a rehabilitation facility on hospital day 48 .

\section{Discussion}

ASAS due to spinal cord infarction is very rare and the diagnosis is challenging when encountered in a previously healthy young patient. Our patient was previously healthy, and extensive investigations including laboratory screening for autoimmuneassociated vasculitis, infections, hypercoagulopathies, and CSF analysis identified no risk factors. Severe neck pain 2 days before admission was an alarming sign of ASAS, but it might be impossible to consider ASAS in a patient without any risk factors and MRI did not seem to reveal any abnormalities on admission. Young patients have been described in several previous studies, but those cases mostly involved children, adolescents, or young patients with previous trauma or angioma [7-9]. Emergency physicians must therefore consider ASAS when encountering a patient with sudden onset of quadriplegia, even if the patient is previously healthy and young.

We should consider differential diagnosis including autoimmune disease, infectious disease such as human T-lymphotropic virus type I (HTLV-I) associated myelopathy, and HIV infection, drug use, and longstanding syphilis in addition to structural vascular disease. These differential diagnoses were all denied due to her history and laboratory test with MRI. Given the sudden onset of neck pain, the possibility of a vascular dissection should be considered, and we thought vertebral artery dissection was the most possible diagnosis when she was transferred. MRI is also good diagnostic tool for vascular disease $[10,11]$.

MRI findings in the early stage are usually ambiguous, and correct interpretation is difficult for emergency physicians, but ASAS must be considered once spinal epidural hematoma has been ruled out by CT and MRI. We have previously reported that MRI can detect ASAS using a combination of DWI with ADC mapping in the early stage [6].

No standardized guidelines have been set for the treatment of ASAS. A previous retrospective study did not show any difference in the clinical course of patients who received antiplatelet therapy, even if they received treatment with corticosteroids or anticoagulation (heparin) [12]. We used edaravone for 14 days, heparin for 21 days, aspirin and steroid pulse therapy (methylprednisolone $1000 \mathrm{mg}$ /day for 5 days first and 3 days later) in the early stage. She was able to move her left arm with biceps MMT 4/5, and right arm with biceps MMT 3/5 (Table 1) on hospital day 48, although sensory deficit remained below the T4 level, which was much better than we had predicted. These effects might have been due to early combination therapy with edaravone, heparin, aspirin, and steroid usages. In contrast, no previous ASAS cases used such a combination therapy and neurological outcomes were 
unfavorable. Long cord lesions, severe initial impairment with weakness, and female sex have been reported as predictors of unfavorable outcomes $[13,14]$. In our case, the patient had all these unfavorable predictors, but could move her left hand and eat unassisted. However, she could not stand unaided, was wheelchair-bound, and was still experiencing bladder dysfunction when transferred from our facility. Symptoms were better than we predicted based on initial MRI showing long cord lesions from $\mathrm{C} 3$ to $\mathrm{T} 1$ and complete flaccid quadriplegia without pain or temperature sensation.

In conclusion, ASAS can cause sudden onset of neck pain with quadriplegia in a young healthy woman, and DWI of the spine should be considered for early diagnosis of ASAS. Early combination treatment with edaravone, antiplatelet agents, corticosteroids and anticoagulants heparin, and aspirin with steroid pulse might be beneficial for patients with ASAS.

Abbreviations ADC, Apparent diffusion coefficient; ASAS, Anterior spinal artery syndrome; CSF, Cerebrospinal fluid; CT, Computed tomography; DWI, Diffusion-weighted imaging; ER,, Emergency room; ICU, Intensive care unit; MMT, Manual muscle testing; MRI, Magnetic resonance imaging

Acknowledgements Not applicable

Code Availability Not applicable

\section{Notice of Prior Abstract Publication/Presentation None}

Authors' Contributions $\mathrm{KoO}$, SO, YO, MO, NO, YS, and HY treated the patient and made the clinical diagnosis. $\mathrm{KoO}, \mathrm{KaO}$, and AT wrote and revised the manuscript. All authors have read and approved the manuscript.

Funding No funding was received for the study.

Data Availability The datasets used during the current study are available from the corresponding author on reasonable request.

\section{Declarations}

Competing Interests The authors declare that they have no competing interests.

Ethics Approval Not applicable

Consent to Participate Not applicable

Consent for Publication Informed consent was obtained from the patient and documented based on local regulations.

Open Access This article is licensed under a Creative Commons Attribution 4.0 International License, which permits use, sharing, adaptation, distribution and reproduction in any medium or format, as long as you give appropriate credit to the original author(s) and the source, provide a link to the Creative Commons licence, and indicate if changes were made. The images or other third party material in this article are included in the article's Creative Commons licence, unless indicated otherwise in a credit line to the material. If material is not included in the article's Creative Commons licence and your intended use is not permitted by statutory regulation or exceeds the permitted use, you will need to obtain permission directly from the copyright holder. To view a copy of this licence, visit http://creativecommons.org/licenses/by/4.0/.

\section{References}

1. Corwell BN, Davis NL. The emergent evaluation and treatment of neck and back pain. Emerg Med Clin North Am. 2020;38(1):16791. https://doi.org/10.1016/j.emc.2019.09.007.

2. O'Phelan KH, Bunney EB, Weingart SD, Smith WS. Emergency neurological life support: spinal cord compression (SCC). Neurocrit Care. 2012;17(Suppl 1):S96-101. https://doi.org/10.1007/s12028-012-9756-3.

3. Novy J, Carruzzo A, Maeder P, Bogousslavsky J. Spinal cord ischemia. Arch Neurol. 2006;63(8):1113-20. https://doi.org/10. 1001/archneur.63.8.1113.

4. Kuker W, Weller M, Klose U, Krapf H, Dichgans J, Nagele T. Diffusion-weighted MRI of spinal cord infarction. J Neurol. 2004;251(7):818-24. https://doi.org/10.1007/s00415-004-0434-z.

5. Weidauer S, Nichtweiß M, Hattingen E, Berkefeld J. Spinal cord ischemia: aetiology, clinical syndromes and imaging features. Neuroradiology. 2015;57(3):241-57. https://doi.org/10.1007/ s00234-014-1464-6.

6. Ota K, Iida R, Ota K, Sakaue M, Takashima S, Taniguchi K, et al. Atypical spinal cord infarction: a case report. Med (United States). 2018;97(23):97-100. https://doi.org/10.1097/MD. 0000000000011058.

7. Foo D, Rossier $A B$. Anterior spinal artery syndrome and its natural history. Paraplegia. 1983;21(1):1-10. https://doi.org/10.1038/sc.1983.1.

8. Safadi W, Srour S, Waksman I. Infarction of the cervical spinal cord in a 20 -year-old healthy man resulting in complete quadriplegia. BMJ Case Rep. 2013;2013:1-3. https://doi.org/10.1136/bcr-2013-009359.

9. Sohal AS, Sundaram M, Mallewa M, Tawil M, Kneen R. Anterior spinal artery syndrome in a girl with down syndrome: case report and literature review. J Spinal Cord Med. 2009;32(3):349-54. https://doi.org/10.1080/10790268.2009.11760789.

10. Hakimi R, Sivakumar S. Imaging of Carotid Dissection. Curr Pain Headache Rep. 2019;23(1):1-7. https://doi.org/10.1007/s11916019-0741-9.

11. Edjlali M, Qiao Y, Boulouis G, et al. Vessel wall MR imaging for the detection of intracranial inflammatory vasculopathies. Cardiovasc Diagn Ther. 2020;10(4):1108-19. https://doi.org/10. 21037/cdt-20-324.

12. de Seze J, Stojkovic T, Breteau G, et al. Acute myelopathies: clinical, laboratory and outcome profiles in 79 cases. Brain. 2001;124(Pt 8):1509-21. https://doi.org/10.1093/brain/124.8.1509.

13. Kameda T, Doi H, Kawamoto Y, Johmura Y, Takahashi T, Koyano $\mathrm{S}$, et al. Clinical features and prognosis in 14 cases of spinal cord infarctions. Jpn J Stroke. 2010;32(4):351-6. https://doi.org/10. 3995/jstroke.32.351.

14. Nedeltchev K, Loher TJ, Stepper F, Arnold M, Schroth G, Mattle HP, et al. Long-term outcome of acute spinal cord ischemia syndrome. Stroke. 2004;35(2):560-5. https://doi.org/10.1161/01.STR. 0000111598.78198.EC

Publisher's Note Springer Nature remains neutral with regard to jurisdictional claims in published maps and institutional affiliations. 